\title{
Trafficking and human rights in Nepal: Community perceptions and policy and program responses
}

Celine Daly

Vaishali Sharma Mahendra

Pankaja Bhattarai

Nick Langton

Jyoti Sanghera

See next page for additional authors

Follow this and additional works at: https://knowledgecommons.popcouncil.org/departments_sbsr-hiv

Part of the Gender and Sexuality Commons

How does access to this work benefit you? Let us know!

\section{Recommended Citation}

Daly, Celine, Vaishali Sharma Mahendra, Pankaja Bhattarai, Nick Langton, Jyoti Sanghera, Catrin Evans, Ratna Kapur, Dill Ram Dahal, and Siobhan Crowley. 2001. "Trafficking and human rights in Nepal:

Community perceptions and policy and program responses," Horizons Research Summary. Washington, DC: Population Council. 


\section{Authors}

Celine Daly, Vaishali Sharma Mahendra, Pankaja Bhattarai, Nick Langton, Jyoti Sanghera, Catrin Evans, Ratna Kapur, Dill Ram Dahal, and Siobhan Crowley 


\section{TheAsia ${ }_{\text {Foundation }}$

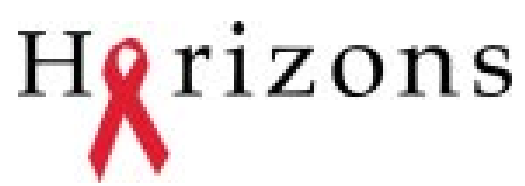

AUGUST 2001

\section{RESEARCH SUMMARY}
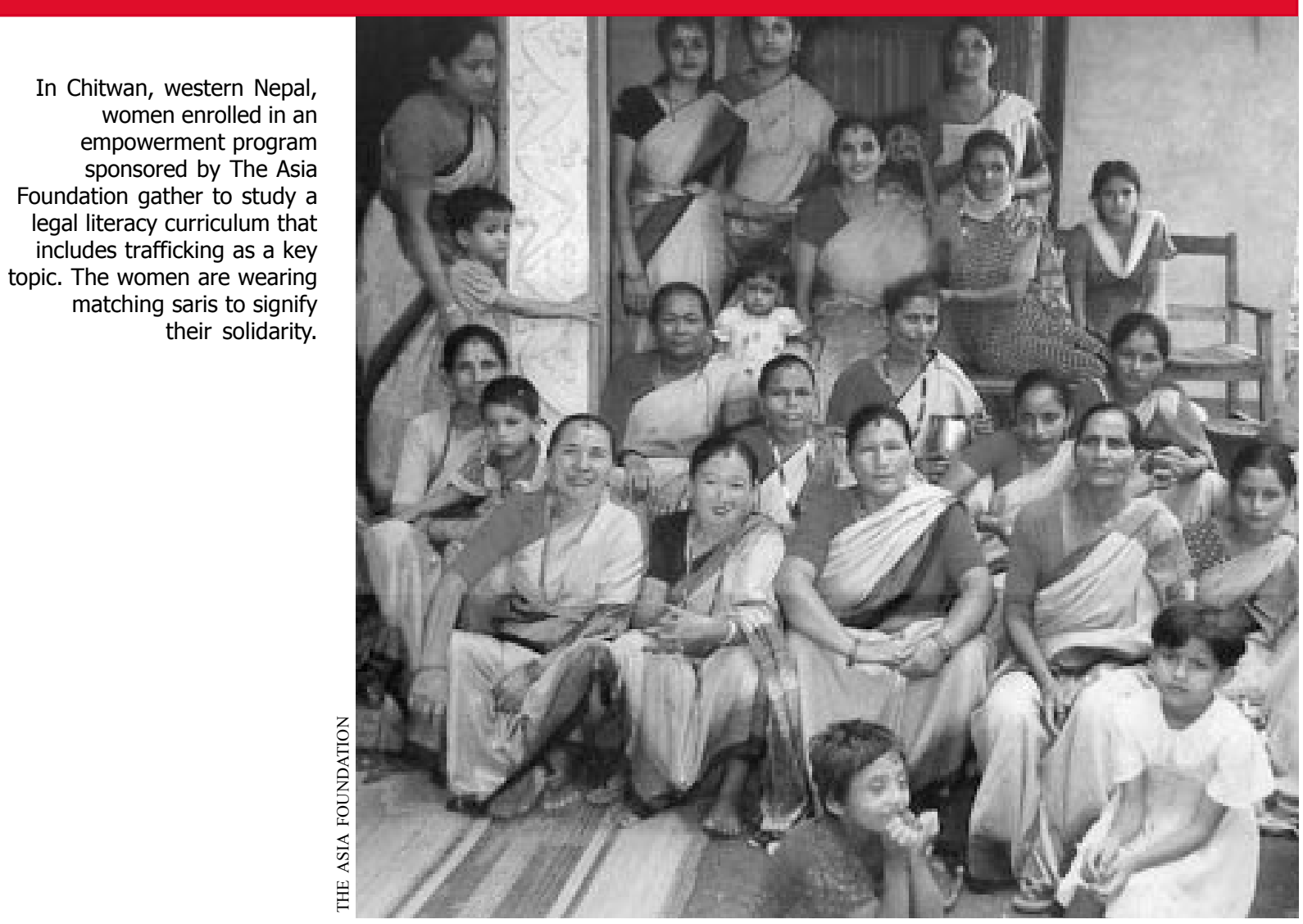

\section{TRAFFICKING AND HUMAN RIGHTS IN NEPAL: COMMUNITY PERCEPTIONS AND POLICY AND PROGRAM RESPONSES}

\section{I} $n$ recent years, millions of women and girls have been trafficked across national borders and within countries, a global industry that generates up to US \$7 billion annually (Widgren 1994). The trafficking problem is particularly acute in Nepal, one of the least developed countries in the world, with 42 percent of its citizens living below the poverty line.

While there are no reliable data on the magnitude of the trafficking problem in Nepal, the most widely quoted sources estimate that 5,000 to 7,000 girls are trafficked from Nepal to India and other neighboring countries every year, primarily for prostitution, and 200,000 Nepali girls and women are currently working in the sex industry in India (UNIFEM 1998). ${ }^{1}$

The occurrence of trafficking in Nepal is generally attributed to widespread poverty, low status of girls and women, and social disparities rooted in ethnic and caste groupings. Women living in an environment of restricted rights, limited personal freedom, and few employment opportunities may decide that out-migration is their only hope for achieving economic independence and a higher standard of living. Those who are victimized by traffickers instead experience abuse, exploitation, and greater vulnerability to HIV/AIDS.

How effective are Nepal's policies and programs in shaping a cohesive and effective 
national anti-trafficking strategy? What are the underlying attitudes and values about trafficking that inform these efforts, and what effect do these assumptions have in practice? Are prevention, care, and support activities for trafficked women and girls appropriate and respectful of their human rights?

A recently completed operations research project undertaken in Nepal by The Asia Foundation and the Horizons Program examines these questions and recommends approaches to strengthen anti-trafficking interventions in the region and to provide effective care and support to trafficked women and girls. The researchers assess Nepal's efforts through a human rights lens, focusing not only on the abuse of fundamental rights that trafficking represents but also on the need to protect women's right to freedom of movement and to employment.

\section{Study Methodology}

The study included three interrelated components:

Policy analysis: A rapid assessment of the policy context that underlies efforts to control trafficking in Nepal. This assessment examined the forces that influence strategic approaches, program priorities, intervention design, and funding opportunities for the prevention of trafficking and the care and support of trafficked persons. The methods included documentation review and interviews with key policymakers, program managers, and activists in Nepal.

\section{Documentation of current intervention}

models: An assessment and analysis of existing, "on-the-ground" intervention programs for the control of trafficking in Nepal. This analysis paid particular attention to the operating values, goals, and strategies of the different interventions, highlighting assumptions about the underlying determinants of trafficking as well as the means of prevention and assistance to trafficked persons. The methods included interviews with individuals and key organizations (one donor agency, ten Kathmandu-based and international NGOs, and two anti-trafficking networks) involved in anti-trafficking activities in Nepal and a review of project documents and IEC materials.

\section{What is Trafficking?}

A recent definition of trafficking proposed by the United Nations Special Rapporteur to the United Nations Commission on Human Rights encapsulates a process of recruitment, transportation, and exploitative labor conditions:

"Trafficking in persons means the recruitment, transportation, purchase, sale, transfer, harboring or receipt of persons by threat or use of violence, abduction, force, fraud, deception or coercion (including the abuse of authority), or debt bondage, for the purpose of placing or holding such person, whether for pay or not, in forced labor or slaverylike practices, in a community other than the one in which such person lived at the time of the original act described." (Coomaraswamy 2000)

\section{Community-based study on trafficking:}

Primary field-based data collection to identify perceptions, knowledge, and attitudes of community members about trafficking, the roles and opportunities ascribed to women, and the benefits of migration to seek work. Participants included adolescent girls and their families, as well as key gatekeepers and decision-makers at the community level. The research team carried out data collection, using both qualitative and quantitative research methods, in three districts in Nepal: Jhapa, Parsa, and Palpa. This included key informant interviews, 43 focus group discussions with adolescent girls and other community members, and Participatory Learning and Action techniques. In addition, the researchers surveyed 1,269 randomly selected adolescent girls (ages 14 to 19) in the three districts.

${ }^{1}$ These reports are not based on empirical data and have not changed since they were first quoted in 1986 . 


\section{Key Findings}

\section{Conceptual clarity is an important element of a comprehensive and consistent response to trafficking.}

The definition of trafficking varies considerably between law and policy documents in Nepal. While the government of Nepal has made considerable effort to address the problem of trafficking, the definition of trafficking varies widely between current laws and policies. The anti-trafficking law (1986) provides protection against the explicit "buying and selling" of human beings for any purpose but does not cover recruitment by deception for the purposes of bonded labor unless it is for prostitution. The new reform bill proposed in 1999 by the Ministry of Women and Children's Social Welfare (MOWCSW) includes bonded labor and enslavement within its definition of trafficking, in keeping with the United Nations definition. However, it goes on to include prostitution, sexual abuse, rape, kidnapping, and pornography as "trafficking," even though each of these issues raises distinct and separate concerns and must be addressed by separate pieces of legislation.

\section{Distinctions between trafficking of women} versus trafficking of children are not made in policy and law documents. Nepal's National Plan of Action Against Trafficking (1999) is largely derived from a consultative workshop with the International Labor Organization and the International Programme on the Elimination of Child Labor (ILOIPEC). Not surprisingly, a large proportion of its recommendations focus on the trafficking of children. However, when the issues surrounding trafficking of women are not considered separately from those of children, the specific needs of neither group receive adequate attention.

The major issue differentiating the prevention and control of trafficking of women versus children is the role of consent. It is important that definitions of trafficking of women include the element of deception and/or coercion - the absence of informed consent. If not, merely assisting a woman to migrate voluntarily becomes a trafficking offense.

\section{The links between trafficking and prostitution are over-emphasized.}

Laws and policies focus solely on trafficking for prostitution. Although it is widely believed that most girls and women in Nepal are trafficked for prostitution, there are no reliable data on the proportion of girls trafficked for prostitution versus other outcomes of trafficking such as forced marriages, domestic labor, bonded labor in circuses, and so on.

\section{Criminalization of prostitution to control} trafficking denies redress to victims. The trafficking reform bill proposed by MOWCSW criminalizes prostitution. If it passes, it would effectively deny redress for women trafficked into prostitution. The proposed legislation uses the platform of trafficking to establish laws to "maintain the good conduct, morality and etiquette of the public." Linking trafficking to a moral issue such as prostitution and labeling trafficked women as immoral undermines the intent of the bill: to prosecute traffickers and protect victims of trafficking.

\section{Fear-based prevention messages link traf-} ficking to prostitution and HIV. NGO prevention messages also often emphasize trafficking for the purpose of prostitution. Many of the IEC materials utilize gruesome descriptions of sex work and HIV infection. These messages use fear to prevent women from leaving their

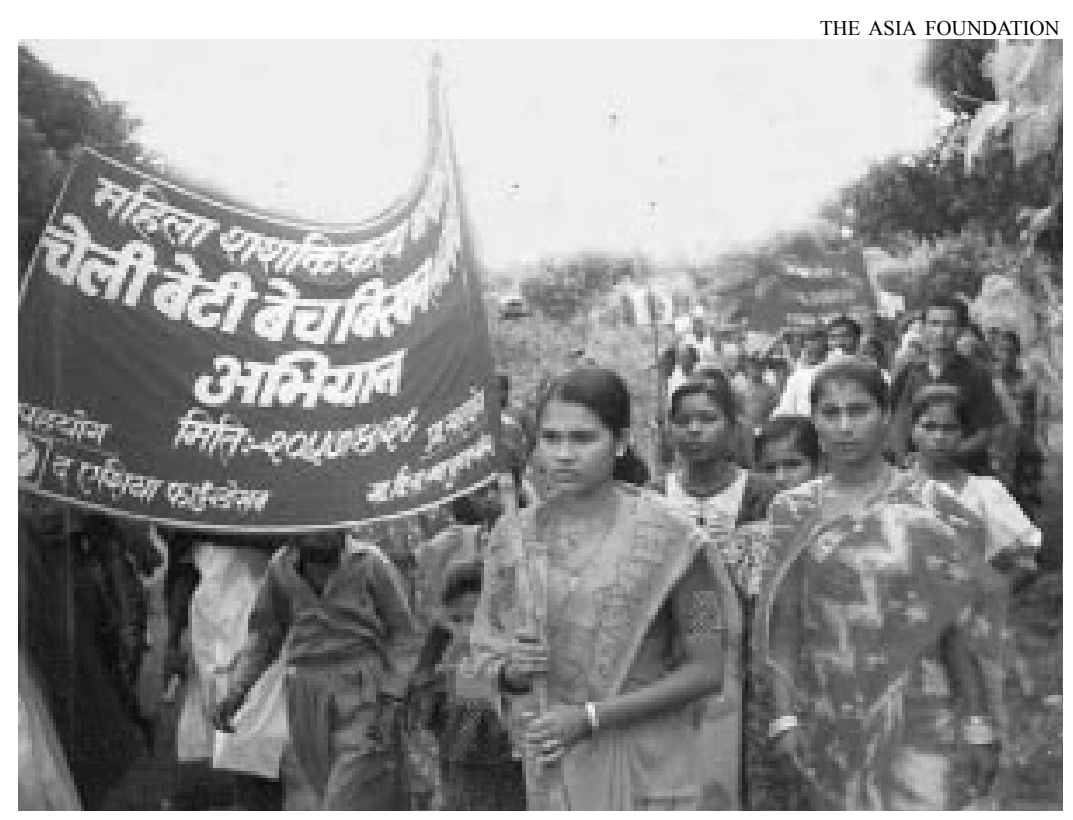

A rally in Jhapa against trafficking in May 2000. 
homes, rather than giving practical advice on decision-making in the difficult circumstances that they may want to escape. Some organizations also associate trafficking with contracting HIV without regard for the stigma that this may falsely create for those who migrate.

\section{Communities associate trafficking with} prostitution and immorality. Among adolescent girls interviewed, 72 percent had heard of trafficking. More than 90 percent of girls said that trafficking involves prostitution and crossborder travel, and in focus group discussions, most community members defined it as selling girls into brothels in India. Respondents also reported that returned trafficked persons face a high degree of stigma and discrimination, often tied to their perceived involvement in prostitution and possible threat of HIV infection. Although communities recognize the role of social and economic hardships in vulnerability to trafficking, they also blame the "immoral" character of the trafficked girl herself. Girls who seek independence, want exposure to the world outside, and are tempted by the prospect of gaining material benefits are perceived as "bad" and more likely to be trafficked.

\section{Efforts to prevent trafficking often limit women's voluntary migration.}

\section{Controlling women's migration is unlikely to prevent trafficking and compromises} women's rights to mobility. A common approach to the control of trafficking in Nepal is the limitation of women's migration. Although specific anti-trafficking laws and policies in Nepal are generally silent on migration, several recent laws and orders, such as the Foreign Employment Act, specifically limit the international migration of women. Stricter border controls will stop neither trafficking nor migration. Traffickers will merely devise increasingly innovative and underground ways of transporting women and girls across the border. Other South Asian neighbors such as Bangladesh have experimented with strict immigration control at the border and a passport system, yet the problem of trafficking is reportedly growing.

In the field study, community respondents reported mixed feelings about women's migration, expressing reserved support when it takes place for "honorable" work that supplements family income - yet also concern about the potential negative consequences of exposure to new environments and experiences. Most of these experiences were believed to spoil the woman's character and make her more likely to enter the sex trade. Migration was also perceived to increase the risk of being trafficked.

"We are not allowed any freedom of movement and at times when we do go out alone, people say evil things to us." (Adolescent girl)

NGOs encourage girls to stay in their villages to prevent trafficking, but a high proportion want to migrate. Many NGOs encourage girls to stay in their villages to prevent trafficking, urging girls "not to be so modern, work hard, be patient, and stay at home." However, 40 percent of surveyed adolescent girls - especially those with higher levels of education - indicated that they do not want to permanently reside in their current villages. An even higher proportion (85 percent) expressed the desire to travel to urban areas. This suggests that trafficking prevention messages that encourage adolescent girls to stay in the village may not be relevant to their needs and aspirations. Since many girls are likely to travel and/or migrate at some time in the future, it is essential to provide the information and skills necessary to navigate the outside world safely for gainful employment.

\section{Interception strategies have not been tested} for accuracy or effectiveness. Interception strategies for controlling trafficking include community surveillance and border-based rescue programs. Community surveillance is a feature of most community-based interventions and allows communities to take substantive action. Several NGOs report that surveillance is effective, citing numerous examples where groups intercepted brokers accompanying girls or where they could report that no girls left or were missing from a community.

One NGO actively attempts to intercept girls and women at border points between Nepal and India in collaboration with the police. Trafficking is suspected in cases where the suspected victim gives hesitant or conflicting answers to questioning. At present, no data are available on the accuracy of this method for identifying trafficked persons or the proportion of intercepted women who are trafficked again later. If the strategy labels voluntary migrants as victims of trafficking, women's right to travel or 
migrate in search of livelihood may be inadvertently compromised. Indeed, there have been reports of women and girls who have been prevented from crossing the border of Nepal despite their vehement protestations that they are traveling of their own free will.

\section{More effective strategies for the prevention, care, and support of trafficked persons are needed.}

\section{Safe migration advice and support are}

crucial. Although communities regard migration as a necessary livelihood strategy even for women, the mobility of adolescent girls is limited to prevent the development of a "loose" character. One-fourth of girls reported that they had never left their village, and others left mostly in the company of friends and family. Adolescent girls spend much of their days (13-17 hours) studying and/or working in the household and on the farm, leaving them little time for developing social networks or for travel. Overall, the emerging picture is one of adolescent girls who are somewhat protected from and inexperienced in navigating the world outside their villages.
Only three of the ten NGOs interviewed give advice for women on what to do if approached by someone to leave their homes for work or marriage. This includes such suggestions as obtaining the address of the employer, having a guardian accompany them to their jobs, and being wary of strangers. While such advice takes the first step of acknowledging that women and girls migrate, it may not be enough to safeguard them. In cases where women are trafficked by those known to them, they may trust them and not perceive a risk at all. Adolescent girls more frequently implicated family (33 percent), other relatives (58 percent), and community members (70 percent) as those responsible for trafficking than strangers (11 percent). Simply accompanying girls to a workplace or taking down the address of the workplace may not prevent trafficking from the work site (which, according to the NGOs, is a growing trend in Nepal).

Evaluation of these messages and the development of new messages are urgently required to safeguard migrating women and girls. New networks designed to support women at their destinations may provide protection.

\section{Intervention Responses to Address Trafficking in Nepal}

\section{Prevention Activities}

Awareness raising, advice giving, and social mobilization (rallies, IEC materials, peer education, organization of women's groups, etc.)

Improvement of livelihood opportunities (income generation, vocational training, micro-credit)

Interception of suspected trafficking victims (community surveillance and border-based rescue)

\section{Care and Support Activities}

Care and support for women/girls who return home

Residential care for girls who do not or cannot return home

Care and support of wenwomen/HIV-positive girls

Legal assistance for trafficked women/girls
Findings

Few interventions provide relevant, realistic messages about trafficking; information and support systems for safe migration also lacking.

Most programs offer training only in traditional, lowincome skills, such as sewing; the aim is primarily to keep girls from leaving the village.

The accuracy of the methods used to identify trafficked persons as opposed to legitimate migrants/travelers is unclear and needs evaluation.

Family assessment is not comprehensive or systematic. Empowerment-oriented approaches, non-traditional skills training, and job placement hold more promise than welfare-oriented approaches.

Limited options available (return home or stay in residential care). Need more planning for girls' futures.

HIV-positive returnees face double stigma. There is no public health rationale for segregation of HIV-positive girls, as is done by one major NGO.

More resources are required for assistance during the 2-5 year court process. 
Return to families and communities must be carefully considered. Care and support programs primarily aim to return girls and women to their communities, but NGOs acknowledge that not all of them want to or can return. Some girls leave difficult or abusive family situations. Others are reluctant to return due to the high level of stigma associated with trafficking, sex work, and HIV and the publicity (often by the NGOs themselves) given to the link between working in India and being HIV-infected.

This raises the questions of how to best facilitate a return to the community when appropriate and what to do for girls who are unable or unwilling to return. Most NGO programs tend to be prescriptive, telling returned girls what they should do, counseling them to return home, and advising families to accept them back. Family assessment is insufficient or ad hoc. There is little emphasis on exploring a girl's feelings or working through family problems, or on follow-up once they leave a shelter. Most vocational training offered to returnees tends to emphasize traditional skills, such as sewing or knitting, that often do not provide adequate income. Options are very limited for girls who do not return home; most remain in residential homes on a long-term basis.

\section{Stricter border controls will stop neither} trafficking nor migration.

More research and resources are required to determine the situation of returned girls and to develop effective support and care strategies. Two organizations have begun to develop alternative ways of supporting trafficking survivors that emphasize building self-esteem and fostering independent living, but no evaluation of this approach has been carried out.

More resources are required for legal assistance. Two NGOs are currently working to prosecute traffickers and help trafficking victims present their cases in court. An average case lasts from two to five years, and NGOs need to remain in contact with and support the women throughout the entire period of interaction with an often unsympathetic court system. The cases should also be documented so that the ongoing problems and issues can be raised in advocacy work with the judiciary.
Clear guidelines for the care of HIV-positive returnees must be developed. Some girls and women who return from trafficking are HIVpositive, although exact figures are not available. They are faced with the double stigma of trafficking and HIV. Current laws and policies do not include guidelines for HIV testing, preand post-test counseling, confidentiality, or continuing care and support for HIV-positive returnees. One NGO segregates HIV-positive girls in an AIDS hospice in a remote district, with no-long term plans for their return. This strategy has no public health justification and warrants careful evaluation.

\section{The lack of program evaluation makes it impossible to assess the effective- ness of trafficking interventions.}

No substantive program evaluation or impact assessment has been carried out. No definitive assessment of the effectiveness of intervention models, activities, and approaches can be made, since current trafficking interventions lack comprehensive and systematic monitoring and documentation. The limited documentation that exists generally focuses on process monitoring. Examples include records of the number of rallies held by women's groups, the number of times that women's groups discuss trafficking, the number of participants in prevention activities, the number of IEC materials produced and distributed, and the number of women and girls intercepted through border rescue or community surveillance strategies.

In an effort to measure outcomes, some NGOs monitor the number of women and girls leaving the village. However, such indicators are not able to distinguish between trafficking and legitimate migration and therefore do not accurately measure the desired outcome of reduction in trafficking at the village level. More information is needed on the process of both trafficking and migration in order to develop indicators that can distinguish between the two.

\section{There is an urgent need to develop and test} process and outcome indicators. In general, organizations need technical support to develop appropriate indicators that take into account trafficking and migration dynamics. This may require formative research, since little is known about the processes of trafficking and the needs of returned trafficked persons. NGOs may also 
require assistance to develop appropriate evaluation methodologies and carry out baseline and follow-up measurements of indicators.

\section{Learning from HIV/AIDS Policies and Programs in Nepal}

Both HIV/AIDS and trafficking control programs work with vulnerable and disempowered populations, involve stigma and discrimination against affected and infected persons, and require similar rights-based responses. There is considerable overlap in targeting beneficiaries of trafficking and HIV/AIDS programs since a proportion of sex workers, migrants, and people living with HIV/AIDS (PLHA) have been trafficked, and trafficked persons are at increased risk for HIV.

\section{HIV/AIDS control policy in Nepal is rights- based and focuses on empowerment. Many features of current and proposed anti-trafficking laws, policies, and approaches are in direct conflict with the national HIV/AIDS strategic plan. Lessons can be learned from HIV/AIDS control programs that directly apply to the control of trafficking. The National HIV/AIDS Strategic Plan devotes an entire section to the "Legal, Ethical, and Human Rights Aspects of the HIV Epidemic" and aspires to the creation of an "enabling environment." Although mobile populations and sex workers are known to be at increased risk for HIV infection, HIV control}

\section{Study Recommendations}

Promoting human rights and safe migration underlies the policy, program, and research recommendations that emerged from this study. This kind of focus may help overcome some of the ideological differences that currently divide the field in Nepal.

\section{Policy}

- Adopt the trafficking definition of the United Nations Special Rapporteur on Violence Against Women to protect the rights of all trafficked persons, including those who are trafficked for purposes other than prostitution.

- Develop laws and policies to protect the legal and constitutional rights of stigmatized communities, including those who are HIV-positive or engaged in sex work. Oppose laws that criminalize prostitution.

- Promote consistency between HIV/AIDS and trafficking control policies and approaches. Use as a model the National Strategic Plan on HIV/AIDS in Nepal, which incorporates human rights principles.

- Put in place clear guidelines for voluntary HIV testing and counseling of the returned trafficked girls and women and for the ongoing care, support, and reintegration of HIV-positive returnees.

\section{Programming}

- Coordinate advocacy and program efforts so that messages and strategies are consistent.

- Craft prevention messages that include concrete relevant advice on how to migrate safely.

- Establish support systems to enable safe migration and to help women once they reach their destination.

- Assess border-based prevention strategies to determine their effectiveness and to ensure that women's right to mobility is not being breached.

- Encourage and expand interventions that work from the bottom up, involve communities, build capacity, and provide support, rather than top-down welfare-oriented interventions.

- Provide technical and financial support to develop techniques for family assessment, counseling, intervention, and follow-up of rescued girls.

- Develop appropriate plans for girls who cannot return home, particularly in the area of sustainable livelihoods.

- Support NGOs providing legal aid services to survivors and working to prosecute anti-trafficking cases.

- Document cases for use in advocacy work with the judiciary.

\section{Research}

- Undertake formative research to inform intervention strategies.

- Develop impact indicators and support NGOs in carrying out appropriate monitoring and evaluation. 
efforts have not called for the restriction of migration and prostitution in contrast to antitrafficking policy. Instead, the focus has been on information, education, and empowerment of those populations to prevent transmission. Efforts have also focused on reducing stigma and discrimination toward those already infected and affected, as well as on their empowerment through PLHA networks. The focus on monitoring, evaluation, and impact assessment applied to HIV/AIDS interventions should also be applied to anti-trafficking activities.

Both anti-trafficking and HIV/AIDS programs can benefit from increased collaboration and consistent approaches. An emphasis on human rights may serve as a starting point for a common platform.

The study's investigators are participating in a number of activities to disseminate and discuss the findings with policymakers, NGOs, and activists involved in anti-trafficking, HIV/ AIDS, and broader development issues. The purpose of a September 2001 consultative meeting in Kathmandu sponsored by several international and regional agencies is to mobilize resources to prevent trafficking in South Asia and ensure the reintregration of trafficked persons in ways that safeguard their human rights.

Study investigators include Pankaja Bhattarai and Nick Langton of The Asia Foundation,Kathmandu; Catrin Evans, Jyoti Sanghera, Ratna Kapur, and Siobhan Crowley, consultants; and Vaishali Sharma Mahendra and Celine Costello Daly of Horizons.

\section{References}

Coomaraswamy, Radhika. 2000. "Report on Trafficking by the Special Rapporteur on Violence Against Women, Its Causes and Consequence," submitted in accordance with Commission on Human Rights resolution 1997/44, E/CN.4/ $2000 / 68,56^{\text {th }}$ Session of the Commission on Human Rights.

UNIFEM. 1998. "Trade in Human Misery: Trafficking in Women and Children." New Delhi.

Widgen, Jonas. 1994. "Multinational Cooperation to Combat Trafficking in Migrants and the Role of the International Organizations: International Response to Trafficking in Migrants and Safeguarding of Migrants Rights." IOM Seminar on Trafficking in Migrants and Safeguarding Migrants Rights, Geneva, October 26-28, 1994.

\section{H $\chi^{\text {rizons }}$}

\section{About Horizons}

Horizons is a global operations research project designed to identify solutions to improve prevention, care and support programs, and service delivery.

Horizons is implemented by the Population Council under a cooperative agreement with the U.S. Agency for International

Development. Horizons partners are the International Center for Research on Women (ICRW), the Program for Appropriate Technology in Health (PATH), the International HIV/AIDS Alliance, the University of Alabama at Birmingham, and Tulane University.

Population Council/Horizons

53 Lodi Estate, 3rd Floor

New Delhi 110003

INDIA

Tel: 91-11-464-290/2

horizons@pcindia.org

Population Council/Horizons

Communications Unit

4301 Connecticut Avenue, NW

Suite 280

Washington, DC 20008

Tel: 202-237-9400

Fax: 202-237-8410

horizons@pcdc.org

www.popcouncil.org

This publication was made possible through support provided by the Office of Health and Nutrition, Global

Bureau, U.S. Agency for

International Development, under the terms of HRN-A-00-97-00012-

00 . The opinions expressed herrein are those of the authors and do not necessarily reflect the views of the U.S. Agency for International Development.

\section{CP Population Councl}

C) 2001The Population Council Inc.

To read the full report "Prevention of Trafficking and the Care and Support of Trafficked Persons" on the Population Council website, go to www.popcouncil.org/ pdfs/horizons/trafficking1.pdf. 